\title{
Intensive Therapy of the Respiratory Failure Arising after the Plasty of Large Ventral Hernias
}

\author{
Hasanov FJ*, Musayeva NZ, Asgarova GA and Abbasova MT \\ Department of Anaesthesiology-Reanimation, Azerbaijan Republic Ministry of Health \\ Scientific Surgical Center, Azerbaijan
}

*Corresponding author: Fuad Jalil oglu Hasanov M.D, the chief, Anaesthesiology-

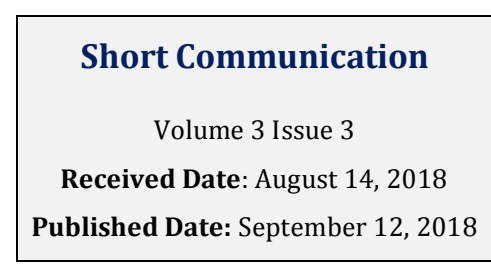

Reanimation Department, The Azerbaijan Republic, Scientific Surgical Center named after acad. M.A. Topchubashev, Baku city, 196 Sharifzadeh street, Azerbaijan, Tel: 994502163199; Email: dr.f.hasanov@gmail.com

\section{Introduction}

The pressure within the abdominal cavity is normally little more than atmospheric pressure [1-3]. However, even small increases in intra-abdominal pressure can have adverse effects on renal function, cardiac output, hepatic blood flow, respiratory mechanics and intracranial pressure [4-6]. Significant increases in intraabdominal pressure are seen in a wide variety of conditions commonly encountered in the intensive care unit [7]. Abdominal compartment syndrome describes the combination of increased intra-abdominal pressure and end-organ dysfunction, has a high mortality $[1,4,8]$. One of the post-operational complications of the plastics of large ventral hernia is the development of respiratory failure (RF) [9]. This is caused by increased intra-abdominal pressure (IAP), encountered in $62 \%$ of patients with large ventral hernia. Prognosis herein is substantially determined by timely compensation of the respiratory malfunction of lungs $[7,9]$.

There search objective - is to define the efficiency of noninvasive artificial ventilation of lungs (NAVL) during $R F$, arising after the plasty of larger ventral hernias.

Keywords: Respiratory failure; Intra-abdominal pressure; Noninvasive ventilation

Abbreviations: IAP: Intra-abdominal pressure; RF: Respiratory failure; AH: Abdominal hypertension; RV: Respiratory volume.

\section{Materials and Methods}

During the period 2007-2014 168 patients with ventral hernia underwent surgical treatment in SSC named after M.A. Topchubashev. Next post- operational period was complicated by acute RF in 62 patients out of them (36.9\%), who made the main group of research. 20 patients who underwent operation because of peptic ulcer of stomach and duodenum were in control group, without any malfunction of respiratory system. Measurement of IAP was conducted by transvesical method before and after NAVL session. Defining IAP higher than $8 \mathrm{~cm} \mathrm{H}_{2} \mathrm{O}$ was considered as the presence of abdominal hypertension (AH).

\section{Results}

The RF diagnosis was established by existence of the following criteria, besides the clinical picture: the oxygenation index $\left(\mathrm{PaO}_{2} / \mathrm{FiO}_{2}<300\right), \mathrm{PaCO}_{2}>45 \mathrm{~mm} \mathrm{Hg}$, $\mathrm{pH}<7.35$, respiratory volume $(\mathrm{RV})<5 \mathrm{ml} / \mathrm{kg}, \mathrm{RR}>25$ a minute. The patients in the main group were divided into 3 groups depending on IAP level. 32 patients with IAP being within 10-15 $\mathrm{cm} \mathrm{H}_{2} \mathrm{O}$ were included in the I group mild degree of $\mathrm{AH}$, and 21 patients with IAP being within 16-20 $\mathrm{cm} \mathrm{H}_{2} \mathrm{O}$, that corresponded to $\mathrm{AH}$ moderate severity were included in the II group. 9 patients with IAP higher than $20 \mathrm{~cm} \mathrm{H}_{2} \mathrm{O}$ - severe degree of $\mathrm{AH}$ were included in the III group.

NAVL began with a standard setting PEEP $=5 \mathrm{~cm} \mathrm{H}_{2} \mathrm{O}$ 


\section{Anaesthesia \& Critical Care Medicine Journal}

and $\mathrm{FiO}_{2}=50 \%$. The duration of the session was 4 hours with intervals of 90 minutes. 5 stages were distinguished during the NAVL: I - RF diagnosing; II - the beginning of NAVL; III - setting of optimal NAVL mode; IV -completion of NAVL and V- transition from NAVL mode to spontaneous respiration. It was decided to use NAVL in case; there exist deterioration in two of the following indicators (in the background of respiration by air):

- $\mathrm{PaO}_{2}$ being less than $55 \mathrm{~mm} \mathrm{Hg}$

- $\mathrm{PaO}_{2} / \mathrm{FiO}_{2}$ less than 280

- $\mathrm{PaCO}_{2}$ more than $45 \mathrm{~mm} \mathrm{Hg}$

- $\mathrm{pH}$ of arterial blood less than 7.35

- $\mathrm{RV}$ less than $4 \mathrm{ml} / \mathrm{kg}$

- RR (respiratory rate) more than 25 a minute.

Positive dynamics were noticed in general condition of patients from the beginning of stage II. During stage III the patients' condition began to improve considerably according to clinical and also gas exchange and hemodynamic indicators. The skin and visible mucous got normal coloring, the humidity of skin was gone, RR and tachycardia decreased, $\mathrm{PaCO}_{2}$ decreased to $44.2 \pm 1.3 \mathrm{~mm}$ $\mathrm{Hg}, \mathrm{PaO}_{2}$ increased up to $96.2 \pm 0.5 \%, \mathrm{PaO}_{2} / \mathrm{FiO}_{2}$ $=276.5 \pm 5$.1indicated the elimination of arterial anoxemia which was present before $(\mathrm{p}<0.01)$. It became possible to separate patients from respiratory mask during $54.5 \pm 2.5$ minutes in stage IV. Respiration was gradually stabilized in $96.4 \%$ of patients in stage $\mathrm{V}, \mathrm{PaO}_{2} / \mathrm{FiO}_{2}$ indicator was inclined to normalization.

\section{Conclusion}

Thus, it was established that applying NAVL after the plasty of large ventral hernia was effective and enabled to refuse a trachea intubation.

\section{Acknowledgements}

Assistance with the study: none

Financial support and sponsorship: none

Conflicts of interest: none

Presentation: this study was presented orally at the $1^{\text {st }}$ Ambroise Pare International Military Surgery Forum 1518 May 2018, in Baku, Azerbaijan.

\section{References}

1. Acta Clinica Belgica (2007) proceedings of the Third World Congress of the Abdominal Compartment Syndrome. Antwerp, Belgium, pp: 113-118.

2. Agnew SP, Small W Jr, Wang E, Smith LJ, Hadad I, et al. (2010) Prospective measurements of intra-abdominal volume and pulmonary function after repair of massive ventral hernias with the components separation technique. Ann. Surgery 251(5): 981-988.

3. Cheatham ML (2009) Nonoperative management of intraabdominal hypertension and abdominal compartment syndrome. World Journal of Surgery 33(6): 1116-1123.

4. Anthony Iacco, Adewunmi Adeyemo, Thomas Riggs, Randy Janczyk (2014) PSingle institutional experience using biological mesh for abdominal wall reconstruction. The American Journal of Surgery 208(3): 480-484.

5. Balogh Z, McKinley BA, Holcomb JB, Miller CC, Cocanour CS, et al. (2003)Both primary and secondary abdominal compartment syndrome can be predicted early and are harbingers of multiple organ failure. J Traumav 54(5): 848-859.

6. Bisgaard $T$, Kehlet $H$, Bay-Nielsen $M$, Iversen $M G$, Rosenberg J, et al. (2011) A nationwide study on readmission, morbidity, and mortality after umbilical and epigastric hernia repair. Hernia 15(5): 541-546.

7. Kristian K Jensen, Nadia A Henriksen, Henrik Harling (2014) Standardized measurement of quality of life after incisional hernia repair: asystematic review. The American Journal of Surgery 208(3): 485-493.

8. Ambrosino N, Vagheggini G (2008) Noninvasive positive pressure ventilation in the acute care setting: where are we? Eur Respir J 31 (4): 874-886.

9. Breuing K, Butler CE, Ferzoco S, Franz M, Hultman CS, et al. (2010) Incisional ventral hernias: review of the literature and recommendations regarding the grading and technique of repair. Surgery 148: 544558.

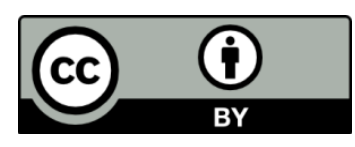

Hasanov FJ, et al. Intensive Therapy of the Respiratory Failure Arising after the Plasty of Large Ventral Hernias. Anaesth Critic Care Med J 2018, 3(3): 000138. 